\title{
Calcium Citrate
}

National Cancer Institute

\section{Source}

National Cancer Institute. Calcium Citrate. NCI Thesaurus. Code C1355.

The citrate salt of calcium. An element necessary for normal nerve, muscle, and cardiac function, calcium as the citrate salt helps to maintain calcium balance and prevent bone loss when taken orally. This agent may also be chemopreventive for colon and other cancers. (NCI04) 